\title{
Altered Chemokine Th1/Th2 Balance in Addison's Disease: Relationship with Hydrocortisone Dosing and Quality of Life
}

Bertil Ekman, N Alstrand, Margareta Bachrach-Lindström, Maria C Jenmalm and Jeanette Wahlberg

The self-archived postprint version of this journal article is available at Linköping University Institutional Repository (DiVA):

http://urn.kb.se/resolve?urn=urn:nbn:se:liu:diva-104003

N.B.: When citing this work, cite the original publication.

Ekman, B., Alstrand, N, Bachrach-Lindström, M., Jenmalm, M. C, Wahlberg, J., (2014), Altered Chemokine Th1/Th2 Balance in Addison's Disease: Relationship with Hydrocortisone Dosing and Quality of Life, Hormone and Metabolic Research, 46(1), 48-53. https://doi.org/10.1055/s-00331351291

Original publication available at:

https://doi.org/10.1055/s-0033-1351291

Copyright: Thieme Publishing

http://www.thieme.com/ 


\section{Altered chemokine Th1 /Th2 balance in Addison's disease: relationship with}

hydrocortisone dosing and quality of life

${ }^{1}$ Bertil Ekman, ${ }^{2}$ Nils Alstrand, ${ }^{3}$ Margareta Bachrach-Lindström, ${ }^{4}$ Maria C Jenmalm, and

${ }^{1}$ Jeanette Wahlberg

${ }^{1}$ Department of Medicine and Health Sciences, Division of Endocrinology, Faculty of Health Sciences, Linköping University, Linköping, Sweden, ${ }^{2}$ Department of Medicine and Health Sciences, Faculty of Health Sciences, Linköping University, Linköping, County Hospital, Kalmar, Sweden, ${ }^{3}$ Department of Medicine and Health Sciences, Division of Nursing Science, Faculty of Health Sciences, Linköping University, Linköping, Sweden, ${ }^{4}$ Department of Clinical and Experimental Medicine, Division of Inflammation Medicine, Faculty of Health Sciences, Linköping University, Linköping, Sweden.

Short title: Th1 /Th2 balance in Addison's disease.

Key words: Adrenocortical insufficiency, cortisol, chemokines, autoimmunity

Word count: 3217.

Address for correspondence: Bertil Ekman, MD

Section of Endocrinology and Diabetology

University Hospital, S-581 85 Linköping, SWEDEN

Tel +46-(0)-101030000, Telefax +46-(0)-101033502.

E-mail Bertil.Ekman@lio.se 


\begin{abstract}
Objective: The adrenalitis found in autoimmune Addison's disease (AAD) is considered having a Th1-driven pathogenesis. Circulating Th1- and Th2-associated chemokines responsible for the trafficking of leukocytes to inflammatory sites are markers for the Th1/Th2 balance.
\end{abstract}

Aim: To assess if the same daily hydrocortisone dose of $30 \mathrm{mg}$ given in either 2 or 4 doses to patients with AAD could affect the Th1/Th2 balance of circulating chemokines.

Methods: Fifteen patients (6 women) with AAD were included in this randomised, placebo controlled, double blind cross-over study. Samples for chemokines, Th1-associated (CXCL10, CXCL11) and Th2-associated (CCL17, CCL22), were drawn 5 times during a 24$\mathrm{h}$ period at the end of each treatment period and analysed with Luminex. Seven control subjects did the same diurnal blood sampling once.

Results: Subjects with AAD had higher median diurnal levels of the Th1-associated chemokines than controls, CXCL10 43 (33-56) pg/ml vs. $22(19-34) \mathrm{pg} / \mathrm{ml}, \mathrm{p}<0.01)$ and CXCL11 (37 (29-48) pg/ml vs. 16 (9-24) pg/ml, p < 0.001), whereas no significant difference was found regarding the Th2-related chemokines. Similar chemokine levels were found when the same hydrocortisone dose of $30 \mathrm{mg}$ was divided in 2 or 4 doses. Levels of CXCL11 correlated negatively with scores of SF-36 domains (high score indicate better health) of General Health $(\mathrm{GH})$ and total score for Physical Component Summary (PCS), and these negative correlations were most pronounced at 04:00 on the 2-dose regimen. Conclusions: Patients with AAD have a dominant Th1 chemokine profile that partially correlates to reduced quality of life. 


\section{Introduction}

Autoimmune Addison's disease (AAD) is a disease mainly caused by autoimmune destruction of the adrenals [1]. Chemokines, a large family of chemoattractants responsible for the trafficking of leukocytes to the site of inflammation, are involved in the pathogenesis of inflammatory and autoimmune diseases $[1,2]$. Chemokines play an important role in several endocrinological autoimmune diseases, such as Hashimoto's thyroiditis, Graves' disease, and type 1 diabetes mellitus [3]. Circulating Th1- and Th2-associated chemokine levels can be used as markers for the Th1/Th2 balance [4]. Thus, Th1 responses increase the levels of the CXCR3 ligands CXCL10 (interferon- $\gamma$ inducible protein 10, IP-10) and CXCL11 (interferon- $\gamma$ inducible $\mathrm{T}$ cell $\alpha$ chemoattractant, I-TAC), while Th2 responses enhance the CCR4 ligands CCL17 (thymus- and activation-regulated chemokine, TARC) and CCL22 (macrophage-derived chemokine, MDC) levels [5]. CXCR3 is preferentially expressed on Th1 cells and CCR 4 on Th2 cells, thus further amplifying Th1 and Th2 immunity, respectively [6].

AAD often coexists with other autoimmune diseases such as T1D, hypothyroidism, pernicious anaemia, vitiligo and celiac disease in Autoimmune Polyglandular Syndrome type 2 (APS 2), and with hypoparathyroidism and mucocutaneus candidiasis in APS 1 [7]. Although different endocrine organs may at least in part share the mechanisms leading to the glandular autoimmune process, the role of chemokines in autoimmune adrenal insufficiency is poorly understood. The adrenalitis in AAD is considered, at least partly, having a cell mediated, and thus Th1 driven, pathogenesis [8,9]. Increased peripheral blood mononuclear cell IFN- $\gamma$ responses to the steroidogenic cytochrome P450 enzyme 21-hydroxylase (21OH), an autoantibody target in PAI, was recently observed in AAD [10]. It has been noted that Th1-mediated diseases tend to lessen in severity during the shift towards a Th2-dominated 
immune response that occurs during pregnancy $[11,12]$. Thus, Th1-mediated autoimmune diseases can possibly be treated with therapy aiming for Th2-deviation, as tested in various studies using different modulatory substances such as progesterone [13]. Although not clearly proven in randomised placebo-controlled studies, accumulated data suggest that the immune modulatory effects of cortisol are more Th2-deviating than overall suppressive [14]. The mechanisms underlying the increased fatigue reported in AAD are not fully understood, but the lack of restoration of a normal diurnal rhythm for cortisol is advocated as the main cause [15]. Supporting this theory, open studies have reported advantages on health related quality of life (HRQoL) in PAI if the same dose of hydrocortisone was divided in three instead of two doses [16,17], or given by continuous hydrocortisone infusion [18]. In addition, we have recently in a double blind manner showed that if the same hydrocortisone dose of $30 \mathrm{mg}$ was divided either in four or in two doses, AAD patients blindly preferred four doses [19]. In this study our primary aim was to investigate the circulating Th1- and Th2associated chemokine levels in AAD in comparison with healthy control subjects. Furthermore, we aimed to investigate if the same daily hydrocortisone dose divided in either two or four doses could affect the Th1/Th2 balance in AAD and how the chemokine levels were related to self evaluated health, sleep and fatigue. 


\section{Subjects and Methods}

\section{Subjects}

Fifteen patients ( 6 women and 9 men) with primary adrenal insufficiency of autoimmune origin (21-OH antibody positive) were included. The mean age at inclusion was $44.6 \pm 15.7$ yrs. The median duration of glucocorticoid replacement therapy since diagnosis was 12 yrs. (range 1-56 yrs.). The inclusion criteria were morning basal cortisol levels below $100 \mathrm{nmol} / \mathrm{L}$ or maximal plasma concentration of cortisol below $300 \mathrm{nmol} / 1$ after stimulation with synthetic ACTH $\left(\right.$ Synachten $\left.{ }^{\circledR}\right)$, and an elevated plasma ACTH concentration determined in a morning sample. Only adult patients above 18 years of age were recruited and patients with diabetes mellitus were excluded. Fourteen of the patients were treated with fludrocortisone. Eleven of the patients had isolated AAD and four patients had in addition autoimmune thyroiditis treated with thyroxine. Seven healthy controls were included (5 women and 2 men; mean age $54.1 \pm 10.2$ years). Characteristics of patients and control subjects are given in Table 1.

\section{Study design}

This study was part of a randomised; placebo controlled, double blind cross-over study (EuduraCT number 2005-001768-30), assessing the effects of the same daily hydrocortisone dose given in either 2 or 4 doses to patients with AAD [19]. All patients were treated with a $30 \mathrm{mg}$ standard dose of hydrocortisone during the whole study. The patients were randomised to receive either $20 \mathrm{mg}$ hydrocortisone at $07: 00 \mathrm{~h}$ and $10 \mathrm{mg}$ at 16:00 $\mathrm{h}$ (two-dose regimen) or $10 \mathrm{mg}$ at 07:00 h, $10 \mathrm{mg}$ at 12:00 h, $5 \mathrm{mg}$ at 16:00 h and $5 \mathrm{mg}$ at 22:00 $\mathrm{h}$ (four-dose regimen). After 4 weeks they switched to the other treatment. Tablets were taken before meals except the evening dose. All patients received tablets four times a day, either hydrocortisone or placebo, to ensure the double blind study procedure. To accomplish this, our pharmacy (Apoteket AB, Produktion \& Laboratorier 141 75, Kungens Kurva, Stockholm, Sweden), 
produced $5 \mathrm{mg}$ hydrocortisone capsules $(\mathrm{HC})$ and identical placebo capsules $(\mathrm{P})$. The four dose schedule was thus $2 \mathrm{HC}+2 \mathrm{P}$ at 07:00 h, $2 \mathrm{HC}$ at 12:00 h, $1 \mathrm{HC}$ and $1 \mathrm{P}$ at 16:00 $\mathrm{h}$ and 1 $\mathrm{HC}$ at 22:00 h. The two dose schedule was $4 \mathrm{HC}$ at 07:00 h, $2 \mathrm{P}$ at 12:00 h, $2 \mathrm{HC}$ at 16:00 h and $1 \mathrm{P}$ at 22:00 $\mathrm{h}$. Seven patients started with four doses and 8 patients with two doses. Diurnal profiles of cortisol in plasma and urine were collected at the end of each treatment and the patients filled out questionnaires, administered once at daytime at the end of each treatment. Chemokines were analysed in the samples collected at 16:00, 20:00, 04:00, 07:00 and 10:30 h. The seven control subjects did the diurnal profiles of cortisol and chemokines once. The control subjects did not fill in the questionnaires.

\section{Cortisol analyses}

Serum cortisol was measured with a commercial kit by fluorescence immunoanalysis on AutoDelfia (Wallac Oy, Finland). The total coefficient of variation (CV) for the serum cortisol assay was $6 \%$ for high values and $8 \%$ for low values and the lower detection limit was $15 \mathrm{nmol} / \mathrm{l}$. Urine cortisol was measured with a commercial kit by radio-immuno-assay (RIA) (Diagnostic Products Corporation, Los Angeles, CA, USA). The total CV for the free urine cortisol analysis was $16 \%$.

\section{Chemokine analyses}

The chemokines CXCL10, CXCL11, CCL17 and CCL22 were analysed on a Luminex ${ }^{100}$ instrument (Biosource, Nivelles, Belgium), as described in detail previously [20]. The data were acquired using the StarStation 2.3 software (Applied cytometry systems, Sheffield, UK) with 5-parametric-curve fitting. The detection limits were $6 \mathrm{pg} / \mathrm{ml}$ for CXCL10 and CCL22, $17 \mathrm{pg} / \mathrm{ml}$ for CXCL11, and $2 \mathrm{pg} / \mathrm{ml}$ for CCL17. All samples were analysed in duplicates and the sample was re-analysed if the coefficient of variance (CV) was $>15 \%$. 
Health related quality of life (HRQoL) and subjective well-being

The patients filled in HRQoL questionnaires administered once at the end of each study period. The questionnaires used were the Short Form-36 (SF-36) [21], the fatigue impact scale (FIS) [22] and the Epworth Sleepiness Scale (ESS-scale) [23].

\section{Ethics}

The study was approved by the local Ethics Committee and performed in accordance with the Declaration of Helsinki. The patients were informed about the purpose of the study and gave their written informed consent.

\section{Statistics}

Statistical calculations were made using SPSS 20 software for Windows. Results are given as medians and $25^{\text {th }}$ to $75^{\text {th }}$ percentiles or when appropriate mean $\pm \mathrm{SD}$. For some comparisons individual means of chemokine levels from all diurnal five-time points were calculated. Area under the curve was calculated using the trapezoid method. Results are given as median and $25^{\text {th }}$ to $75^{\text {th }}$ percentiles (or range) or mean $\pm \mathrm{SD}$ when appropriate. Comparisons within groups were made with Wilcoxon rank sum test for non-normally distributed data or paired 2-tailed ttest if normally distributed data. Comparisons between groups were made with MannWhitney $U$ test for non-normally distributed data or unpaired 2-tailed t-test if normally distributed data. Correlations were made with Spearman's (rho) for non-normally distributed data or Pearson's test (r) if normally distributed data. Statistical significance was considered at the $5 \%$ level $(\mathrm{p}<0.05)$. 


\section{Results \\ Comparison of chemokine levels in AAD vs. controls}

Chemokines were measured at 16:00 h, 20:00 h, 04:00 h, 07:00 h and 10:30 h both in AAD subjects and control subjects. Subjects with AAD had higher levels of the Th1-associated chemokines than controls calculated as individual means of chemokine levels from all diurnal five-time points, during both the 2-dose and the 4-dose regimen (Fig 1, Table 2). On the other hand no significant difference was found between AAD and controls regarding the Th2related chemokines CCL17 and CCL22, neither with 2-dose nor with 4-dose treatment, Table 2. No significant differences were found in chemokine levels between the 2-dose and the 4dose regimen (Table 2). Age or disease duration showed no significant correlations with any of the chemokine levels found in AAD subjects or control subjects. The presence of other concomitant autoimmune disease (four cases of autoimmune thyroiditis) did not significantly influence the chemokine levels in the AAD group.

\section{Diurnal variation of chemokines in AAD and controls}

In subjects with AAD no significant diurnal changes were observed in the Th1-associated (CXCL10, CXCL11) or in the Th2-associated (CCL17, CCL22) chemokines, neither during the 2-dose period nor during the 4-dose period. However, there was a significant higher CXCL11/CCL22 ratio at 04:00 during the 2-dose period 0.18 (0.13-0.28) compared with the 4-dose period $0.15(0.1-0.24), \mathrm{p}=0.017$

In the control group, small diurnal differences were observed in plasma levels of Th1 associated chemokines, CXCL10 levels were significantly higher at 07:00 h compared to levels at 04:00 h: $26.6 \mathrm{pg} / \mathrm{ml}(22.4-34.1) \mathrm{vs} .19 .9 \mathrm{pg} / \mathrm{ml}(17.4-25.7), \mathrm{p}=0.018$, and also CXCL1 1 tended to be higher at 07:00 h compared to 04:00 h: 17.3 (range 8.6-43.8) vs. 8.6 $\mathrm{pg} / \mathrm{ml}$ (range 8.6-29.5) $\mathrm{pg} / \mathrm{ml}, \mathrm{p}=0.068$. For the $\mathrm{Th} 2$ associated chemokines a slightly higher 
value at 07:00 of compared with 04:00 $\mathrm{h}$ was found for CCL22, $251 \mathrm{pg} / \mathrm{ml}$ (174-315) vs. 244 $\mathrm{pg} / \mathrm{ml}$ (143-265), $\mathrm{p}=0.018$, while CCL17 at 07:00 was $66.2 \mathrm{pg} / \mathrm{ml}(39.0-307)$, and at 04:00 $55.4 \mathrm{pg} / \mathrm{ml}(40.9-270)$, n.s.

\section{Chemokines and relation to circulating cortisol levels}

Laboratory data regarding diurnal plasma levels of cortisol are partly described elsewhere [19]. The 24-h area under the cortisol curve (24-h-cortisol $\left.{ }_{\mathrm{AUC}}\right)$ was significantly higher during

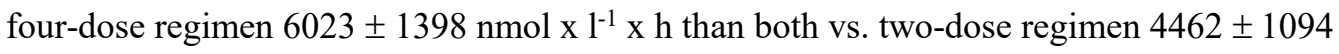
nmol x $1^{-1} \times \mathrm{h}(\mathrm{p}<0.0001)$ and vs. the controls $4342 \pm 848 \mathrm{nmol} \times \mathrm{L}^{-1}, \mathrm{p}<0.0001$. No difference was seen in 24-h urinary free cortisol (24-h UFC) between 4-dose $337 \pm 173$ vs. 2dose $330 \pm 93$, while the control subjects excreted significantly lower 24-UFC $174 \pm 143$ nmol/day, $\mathrm{p}<0.001$, vs. both 4-dose and 2-dose respectively. None of the Th1 or Th2 chemokines measured during the 2-dose period or 4-dose period correlated directly with cortisol neither at any time point measured, nor with 24-h-cortisol ${ }_{\mathrm{AUC}}$ or 24-UFC.

\section{Questionnaires at the end of each study period}

When the values of all 5 time points both for 2-dose and 4-dose measurements for CXCL11 were calculated together negative correlations were observed between CXCL11 levels and the SF-36 domain General Health and Physical component summary (PCS) (Table 3). These correlations were more marked during the 2-dose period, with some significant correlations disappearing during the 4-dose period (Table 3). Although the negative correlations were found at all time points during the 24-h period, the correlations between CXCL11 and domains of the SF-36 were strongest at 04:00 (Fig 2). At this time point, there were also weak negative correlations during the 4-dose treatment (Fig 2). 
When the median values of all 5 time points both for 2-dose and 4-dose measurements for CXCL11 were calculated together, a weak positive correlation $r h o=0.41, p=0.033$ were found with the ESS sum, indicating higher risk of daily sleepiness (Table 3). No significant correlation was found between CXCL11 and the fatigue impact scale (FIS) if all time points were calculated together both for 2-dose and 4-dose (Table 3).

The positive correlation between CXCL11 and the ESS sum remained at 04:00, rho 0.40, p= 0.042 and in addition a borderline positive correlation with FIS sum (high values indicates increased fatigue) $0.34, p=0.087$ was recorded. No significant correlations were observed between CXCL10 and CCL17 and any questionnaire, while for CCL22 and the SF-36 domain General health a significant correlation was found, rho $-0.5, \mathrm{p}<0.001$, (most prominent during the 4-dose period). Age and disease duration showed no significant relationships with individual scores measured in the questionnaires. 


\section{Discussion}

In the present study, AAD was associated with increased Th1 activity, with elevated CXCL10 levels in line with previous studies $[1,24,25]$. The elevation of CXCL11 in AAD compared to control subjects has not been described before and this is contrary to a recent report where CXCL11 levels were not statistically significantly different in patients and controls [25], but in concordance with elevated CXC11 levels found in autoimmune thyroiditis [26]. The IFN- $\gamma$ inducible chemokines (CXCL10, CXCL11) bind to a common receptor, CXCR3, preferentially expressed onTh1 cells, and play important roles in the pathophysiology of autoimmune disease [27]. Almost all research focus has been on CXCL10, although CXCL11 has the highest binding affinity to the CXCR3 receptor and its role in AAD and other autoimmune endocrine diseases has not been fully explored [27].

As the immune modulatory effects of cortisol seems to be more Th2-deviating than overall suppressive [14], one could hypothesize that an increased cortisol level or enhanced cortisol effect should lower the Th1 response. Recently we reported that a four-dose regimen in patients with AAD gave an increased availability of cortisol with significantly higher 24-hcortisol $_{\mathrm{AUC}}$ and an enhanced effect shown by lower morning ACTH levels compared to the same dose divided in two doses [19]. However, in the present analysis we could not confirm the hypothesis that an increased 24-h cortisol exposure should changed the ratio between Th1 chemokines and Th2 related chemokines to a more Th2 deviating status. The absence of correlations between the chemokine and cortisol levels in our patients is intriguing, since cortisol is found to suppress Th1 immune responses [14]. The patients had also a rather high substitution dose of $30 \mathrm{mg}$ compared with $15-20 \mathrm{mg} /$ day proposed in recent years [28]. Our patients probably have no functioning adrenals, since clinical disease appears only after over $90 \%$ of the glands has been destroyed [29] and all our patients had elevated ACTH levels and low morning cortisol levels before tablet intake. One can thus argue that the immunological 
process responsible for the tissue destruction, via lymphocyte infiltration [30], no longer should be active. This paradox could be due to a possible reduction of sensitivity to the immunomodulatory effect of cortisol among patient with AAD, as in accordance with previous findings [1], showing that CXCL10 is induced in the adrenals under influence of pro-inflammatory cytokines. The increased Th1 activity is also in concordance with the enhanced IFN- $\gamma$ secretion to the candidate autoantigen 21-OH in AAD [10]. Our results indicate that conventional substitution with 2-4 daily doses of hydrocortisone could not normalize the disturbed Th1/Th2 balance in AAD.

Our study with randomised, placebo controlled, double blind crossover design allowed us to study patient preference. We found a better preference and a tendency of improvement in all subscales in SF-36 for four doses [19], indicating that the better diurnal coverage of cortisol in some way was better for our patients. However, the stronger negative correlation between Th1 associated CXCL11 and subscales of SF-36 during the two-dose period indirectly indicate that a dosing scheme better covering the day (i.e. four doses) could have beneficial effects on health in AAD via the Th1/Th2 balance. Moreover, our findings that high levels of CXCL11 were associated with lower scores in SF-36 and increased ESS sum (indicating daily sleepiness), could also suggest that other mechanisms than inadequate cortisol replacement therapy could cause fatigue and decreased quality of life found in AAD [31]. In animal models fatigue appears to arise when some stimulus induces increased proinflammatory cytokines in the brain and/or activated microglia or by direct cytokine transport across the blood-brain barrier [32]. Consequently, as many hypothyroid associated symptoms could remain despite optimal replacement therapy, like in autoimmune thyroiditis [33], the autoimmunity in itself may cause disease symptoms in autoimmune diseases including AAD. 
Circadian rhythms are controlled by a pacemaker in the suprachiasmatic nuclei (SCN) in the hypothalamus. A clinical report of a case study with damage to the circadian pacemaker in the SCN suggests that such damage does leave a person feeling fatigued [34]. The lack of the normal cortisol peak during the early morning can not be restored with conventional daily dosing with 2-4 doses short acting hydrocortisone [19,35] or with a newly developed long acting modified release hydrocortisone tablet [36]. Therefore most patients on daily hydrocortisone replacement therapy have hypocortisolism during the early morning. Our results with a stronger negative correlation between Th1 associated CXCL11 and subscales of SF-36 during the night also support the theory of nocturnal hypocortisolism as the dominant cause of reduced quality of life in patients with AAD. Further supporting this theory is the study by Lovas et al., in which the circadian cortisol rhythm in AAD was restored with continuous hydrocortisone infusion [18]. The patients in that study scored over all better in SF-36 scores, with significant improvement in physical functioning and vitality subscales. This is in agreement with our results as high levels of CXCL11 were negatively correlated with lower scores on SF-36 domains for General Health (GH) and total score of Physical Component Summary (PCS), and these correlations were most pronounced at 04:00 $\mathrm{h}$ on the 2-dose regimen (with lowest nocturnal cortisol administration). Moreover, low levels of cortisol during the night could also interfere negatively with sleep and Garcia-Borreguero et al found [37] that cortisol plays a positive, permissive role in REM sleep regulation and may help to consolidate sleep. One striking finding is that it seems that the physical components seem more negatively affected in our and other studies [18] than the mental components. Shortcomings of our study exist with relatively low number of subjects due to the complicated study design and some of the findings between chemokines and the questionnaires could therefore be due to multiple testing. On the other hand, despite the double blind design used in our study, which allows us to compare differences in HRQoL, 
some of the effects could have been masked by the fact that our AAD subjects have normal SF-36 scores compared with the Swedish background population [38], which are in contrast to a large German study showing impaired HRQoL in subjects with primary or secondary adrenal insufficiency [39]. Importantly the strongest correlations between CXCL11 and HRQoL scores were at night, which encourage to further improvements of hydrocortisone tablets aiming to peak in the early morning [40], or further evaluation of continuous hydrocortisone infusion [18]. In parallel one must examine whether autoimmunity itself causes disease symptoms independent of hormonal effects and we suggest CXCL11 as a new marker for further investigations in AAD.

In conclusion, patients with $\mathrm{AAD}$ have a dominant Th1 chemokine profile that partially correlates to impaired quality of life. We could not demonstrate any direct effect on the Th1/Th2 balance by changing from two to four daily doses of cortisol. 


\section{Funding}

Financial support was received from Medical Research Council of Southeast Sweden (04952), and the Linköping University, Sweden.

\section{Contributor ship statement}

JW designed the study analysis and drafted the manuscript together with BE and NA. MCJ stood for expertise regarding chemokine assessments and MB-L for the expertise regarding questionnaires. MCJ and MB-L reviewed and revised the manuscript for intellectual content. All authors approved the final manuscript 


\section{Legends to figures}

Fig 1. Combined values of all measurements at 16:00, 20:00, 04:00, 07:00, 10:30 for

CXCL10 and CXCL11 during 2-dose and 4 dose hydrocortisone regimen in 15 patients with Addison's disease compared with seven healthy control subjects. Medians, $25^{\text {th }}$ and $75^{\text {th }}$ as well as outliers are indicated. ${ }^{*} \mathrm{p}<0.05,{ }^{* *} \mathrm{p}<0.01 * * * \mathrm{p}<0.001$. Mann-Whitney U test.

Fig 2. Data shown for 15 subjects with Addison's disease treated with twice daily or four times daily hydrocortisone doses. Spearman's rank order correlation coefficient (rho) for CXCL11 measured at five times during the 24-h versus the SF-36 domains General Health (b) and Physical Component Summary (a). The white bars represent the values calculated together for both two doses and four doses. The hatched bars represent the two-dose regimen and the black bars the four-dose regimen.

${ }^{*} \mathrm{p}<0.05,{ }^{* *} \mathrm{p}<0.01 * * * \mathrm{p}<0.001$. 


\section{References}

1 Rotondi M, Falorni A, De Bellis A, Laureti S, Ferruzzi P, Romagnani P, Buonamano A, Lazzeri E, Crescioli C, Mannelli M, Santeusanio F, Bellastella A, Serio M. Elevated serum interferon-gamma-inducible chemokine-10/CXC chemokine ligand-10 in autoimmune primary adrenal insufficiency and in vitro expression in human adrenal cells primary cultures after stimulation with proinflammatory cytokines. J Clin Endocrinol Metab 2005; 90: $2357-2363$

2 Lee EY, Lee ZH, Song YW. CXCL10 and autoimmune diseases. Autoimmun Rev 2009; 8: $379-383$

3 Eizirik DL, Colli ML, Ortis F. The role of inflammation in insulitis and beta-cell loss in type 1 diabetes. Nat Rev Endocrinol 2009; 5: 219-226

4 Sandberg M, Frykman A, Ernerudh J, Berg G, Matthiesen L, Ekerfelt C, Nilsson LJ, Jenmalm MC. Cord blood cytokines and chemokines and development of allergic disease. Pediatr Allergy Immunol 2009; 20: 519-527

5 Mantovani A, Sica A, Sozzani S, Allavena P, Vecchi A, Locati M. The chemokine system in diverse forms of macrophage activation and polarization. Trends Immunol 2004; 25: 677686

6 Pease JE, Williams TJ. Chemokines and their receptors in allergic disease. J Allergy Clin Immunol 2006; 118: 305-318; quiz 319-320

7 Betterle C, Zanchetta $R$. Update on autoimmune polyendocrine syndromes (APS). Acta Biomed 2003; 74: 9-33

8 Nerup J, Bendixen G. Anti-adrenal cellular hypersensitivity in Addison's disease. II. Correlation with clinical and serological findings. Clin Exp Immunol 1969; 5: 341-353

9 Freeman $M$, Weetman AP. T and B cell reactivity to adrenal antigens in autoimmune Addison's disease. Clin Exp Immunol 1992; 88: 275-279 
10 Bratland E, Skinningsrud B, Undlien DE, Mozes E, Husebye ES. T cell responses to steroid cytochrome P450 21-hydroxylase in patients with autoimmune primary adrenal insufficiency. J Clin Endocrinol Metab 2009; 94: 5117-5124

11 Doria A, Iaccarino L, Arienti S, Ghirardello A, Zampieri S, Rampudda ME, Cutolo M, Tincani A, Todesco $S$. Th2 immune deviation induced by pregnancy: the two faces of autoimmune rheumatic diseases. Reprod Toxicol 2006; 22: 234-241

12 Wilder RL. Hormones, pregnancy, and autoimmune diseases. Ann N Y Acad Sci 1998; 840: $45-50$

13 Moro MH, Bjornsson J, Marietta EV, Hofmeister EK, Germer JJ, Bruinsma E, David CS, Persing $D H$. Gestational attenuation of Lyme arthritis is mediated by progesterone and IL4. J Immunol 2001; 166: 7404-7409

14 Elenkov IJ. Glucocorticoids and the Th1/Th2 balance. Ann N Y Acad Sci 2004; 1024: 138-146

15 Lovas K, Husebye ES. Replacement therapy for Addison's disease: recent developments. Expert Opin Investig Drugs 2008; 17: 497-509

16 Groves RW, Toms GC, Houghton BJ, Monson JP. Corticosteroid replacement therapy: twice or thrice daily? J R Soc Med 1988; 81: 514-516.

17 Howlett TA. An assessment of optimal hydrocortisone replacement therapy. Clin Endocrinol (Oxf) 1997; 46: 263-268.

18 Lovas K, Husebye ES. Continuous subcutaneous hydrocortisone infusion in Addison's disease. Eur J Endocrinol 2007; 157: 109-112

19 Ekman B, Bachrach-Lindstrom M, Lindstrom T, Wahlberg J, Blomgren J, Arnqvist HJ. A randomized, double-blind, crossover study comparing two- and four-dose hydrocortisone regimen with regard to quality of life, cortisol and ACTH profiles in patients with primary adrenal insufficiency. Clin Endocrinol (Oxf) 2012; 77: 18-25 
20 Abrahamsson TR, Sandberg Abelius M, Forsberg A, Bjorksten B, Jenmalm MC. A

Th1/Th2-associated chemokine imbalance during infancy in children developing eczema, wheeze and sensitization. Clin Exp Allergy 2011; 41: 1729-1739

21 Ware JE, Jr., Sherbourne CD. The MOS 36-item short-form health survey (SF-36). I.

Conceptual framework and item selection. Med Care 1992; 30: 473-483

22 Fisk JD, Ritvo PG, Ross L, Haase DA, Marrie TJ, Schlech WF. Measuring the functional impact of fatigue: initial validation of the fatigue impact scale. Clin Infect Dis 1994; 18 Suppl 1: S79-83

23 Johns MW. A new method for measuring daytime sleepiness: the Epworth sleepiness scale. Sleep 1991; 14: 540-545

24 Bellastella $G$, Rotondi M, Pane E, Costantini S, Colella C, Calemma R, Capone F, Falorni A, Castello G, Sinisi AA, Bizzarro A, Chiovato L, Bellastella A, De Bellis A. Simultaneous evaluation of the circulating levels of both Th1 and Th2 chemokines in patients with autoimmune Addison's disease. J Endocrinol Invest 2011; 34: 831-834

25 Bratland E, Hellesen A, Husebye ES. Induction of CXCL10 chemokine in adrenocortical cells by stimulation through toll-like receptor 3. Mol Cell Endocrinol 2012, DOI:

10.1016/j.mce.2012.09.004:

26 Antonelli A, Ferrari SM, Frascerra S, Di Domenicantonio A, Nicolini A, Ferrari P, Ferrannini E, Fallahi P. Increase of circulating CXCL9 and CXCL11 associated with euthyroid or subclinically hypothyroid autoimmune thyroiditis. J Clin Endocrinol Metab 2011; 96: 1859-1863

27 Rotondi M, Chiovato L, Romagnani S, Serio M, Romagnani P. Role of chemokines in endocrine autoimmune diseases. Endocr Rev 2007; 28: 492-520 
28 Mah PM, Jenkins RC, Rostami-Hodjegan A, Newell-Price J, Doane A, Ibbotson V, Tucker $G T$, Ross RJ. Weight-related dosing, timing and monitoring hydrocortisone replacement therapy in patients with adrenal insufficiency. Clin Endocrinol (Oxf) 2004; 61: 367-375

29 Ten S, New M, Maclaren N. Clinical review 130: Addison's disease 2001. J Clin Endocrinol Metab 2001; 86: 2909-2922.

30 Irvine WJ, Stewart AG, Scarth L. A clinical and immunological study of adrenocortical insufficiency (Addison's disease). Clin Exp Immunol 1967; 2: 31-70

31 Lovas K, Loge JH, Husebye ES. Subjective health status in Norwegian patients with Addison's disease. Clin Endocrinol (Oxf) 2002; 56: 581-588

32 Dantzer $R, O^{\prime}$ Connor JC, Freund $G G$, Johnson $R W$, Kelley $K W$. From inflammation to sickness and depression: when the immune system subjugates the brain. Nat Rev Neurosci 2008; 9: 46-56

33 Ott J, Promberger R, Kober F, Neuhold N, Tea M, Huber JC, Hermann M. Hashimoto's thyroiditis affects symptom load and quality of life unrelated to hypothyroidism: a prospective case-control study in women undergoing thyroidectomy for benign goiter. Thyroid 2011; 21: 161-167

34 Cohen RA, Albers HE. Disruption of human circadian and cognitive regulation following a discrete hypothalamic lesion: a case study. Neurology 1991; 41: 726-729

35 Ekman B, Blomgren J, Andersson PO, Carlsson M, Arnqvist HJ. Variable sensitivity to the glucocorticoid activity of cortisol in patients with primary adrenal insufficiency: assessment with ACTH profiles. Horm Metab Res 2010; 42: 961-966

36 Johannsson G, Nilsson AG, Bergthorsdottir R, Burman P, Dahlqvist P, Ekman B, Engstrom BE, Olsson T, Ragnarsson O, Ryberg M, Wahlberg J, Biller BM, Monson JP, Stewart PM, Lennernas H, Skrtic S. Improved cortisol exposure-time profile and outcome 
in patients with adrenal insufficiency: a prospective randomized trial of a novel hydrocortisone dual-release formulation. J Clin Endocrinol Metab 2012; 97: 473-481

37 Garcia-Borreguero D, Wehr TA, Larrosa O, Granizo JJ, Hardwick D, Chrousos GP,

Friedman TC. Glucocorticoid replacement is permissive for rapid eye movement sleep and sleep consolidation in patients with adrenal insufficiency. J Clin Endocrinol Metab 2000; 85: 4201-4206

38 Taft C, Karlsson J, Sullivan M. Do SF-36 summary component scores accurately summarize subscale scores? Qual Life Res 2001; 10: 395-404

39 Bleicken B, Hahner S, Loeffler M, Ventz M, Allolio B, Quinkler M. Impaired subjective health status in chronic adrenal insufficiency: impact of different glucocorticoid replacement regimens. Eur J Endocrinol 2008; 159: 811-817

40 Verma S, Vanryzin C, Sinaii N, Kim MS, Nieman LK, Ravindran S, Calis KA, Arlt W, Ross RJ, Merke DP. A pharmacokinetic and pharmacodynamic study of delayed- and extendedrelease hydrocortisone (Chronocort) vs. conventional hydrocortisone (Cortef) in the treatment of congenital adrenal hyperplasia. Clin Endocrinol (Oxf); 72: 441-447 
Table 1. Anthropometric data and laboratory tests during treatment with twice daily or four daily hydrocortisone doses in 15 subjects with autoimmune Addison's disease (AAD). In addition seven healthy controls were included. Data shown as mean \pm 1 S.D.

\begin{tabular}{lccc}
\hline & AAD & & Controls \\
\hline $\mathrm{N}$ & 15 & & 7 \\
$\mathrm{M} / \mathrm{F}$ & $9 / 6$ & & $2 / 5$ \\
Age (years) & $44.6 \pm 15.7$ & n.s & $54.1 \pm 10.1$ \\
Weight $(\mathrm{kg})$ & $74.9 \pm 14.2$ & n.s & $76.3 \pm 14.1$ \\
BMI (kg/m $\left.{ }^{2}\right)$ & $23.9 \pm 3.3$ & n.s & $27.3 \pm 4.3$ \\
W/H-ratio & $0.93 \pm 0.06$ & n.s & $0.90 \pm 0.09$ \\
\hline
\end{tabular}


Table 2. Combined values of all chemokine measurements at 16:00, 20:00, 04:00, 07:00 and 10:30 h. Data calculated from both regimens together and each treatment regimen separately in 15 subjects with Addison's disease substituted with twice daily or four times daily hydrocortisone doses. For comparison same measurements were performed in seven controls. Data shown as median $\left(25^{\text {th }}-75 \mathrm{t}^{\mathrm{h}}\right.$ percentile). $* \mathrm{p}<0.05,{ }^{* *} \mathrm{p}<0.01 * * * \mathrm{p}<0.001$ vs. control subjects. Mann-Whitney U test.

\begin{tabular}{lcccc}
\hline pg/ml & Controls & 2-dose + 4-dose & 2-dose & 4-dose \\
\hline CXCL10 - Th1 & $22(19-34)$ & $* * 43(33-56)$ & $* * 43(37-66)$ & $* 43(32-51)$ \\
CXCL11 - Th1 & $16(9-24)$ & $* * * 37(29-48)$ & $* * * 38(32-46)$ & $* * 35(26-52)$ \\
CCL22 - Th2 & $214(173-281)$ & $209(133-259)$ & $227(127-266)$ & $197(136-258)$ \\
CCL17 - Th2 & $60(46-247)$ & $104(74-133)$ & $106(75-157)$ & $103(74-129)$
\end{tabular}


Table 3. Data shown for 15 subjects with Addison's disease treated with twice daily or four times daily hydrocortisone doses. ESS sum, FIS sum and SF-36 domains are correlated against CXCL11 expressed as combined median values of all measurements at 16:00, 20:00, 04:00, 07:00, 10:30 $\mathrm{h}$ for both the 2-dose and 4-dose treatment calculated together and for each treatment regimen separately. ${ }^{*} \mathrm{p}<0.05,{ }^{*} \mathrm{p}<0.01$. rho= Spearman's rank order correlation coefficient.

\begin{tabular}{|c|c|c|c|c|c|c|}
\hline \multirow[b]{2}{*}{ Questionnaires } & \multicolumn{2}{|c|}{$\begin{array}{c}\text { CXCL11 } \\
\text { 2-dose + 4-dose }\end{array}$} & \multicolumn{2}{|c|}{$\begin{array}{c}\text { CXCL11 } \\
\text { 2-dose }\end{array}$} & \multicolumn{2}{|c|}{$\begin{array}{c}\text { CXCL11 } \\
\text { 4-dose }\end{array}$} \\
\hline & rho & $\mathrm{p}$ & rho & $\mathrm{p}$ & rho & $\mathrm{p}$ \\
\hline ESS sum & 0.41 & 0.033* & 0.43 & 0.14 & 0.37 & 0.20 \\
\hline FIS sum & 0.09 & 0.65 & 0.45 & 0.13 & -0.19 & 0.52 \\
\hline SF-36 & & & & & & \\
\hline PF, Physical Functioning & -0.33 & 0.08 & -0.27 & 0.33 & -0.49 & 0.06 \\
\hline RP, Role Physical & -0.1 & 0.59 & $-0,31$ & 0.27 & 0.22 & 0.45 \\
\hline BP, Bodily Pain & -0.19 & 0.32 & -0.19 & 0.5 & -0.12 & 0.68 \\
\hline GH, General Health & -0.49 & $0.006 * *$ & -0.66 & $0.007 * *$ & -0.34 & 0.21 \\
\hline VT, Vitality & -0.1 & 0.62 & -0.44 & 0.1 & 0.24 & 0.38 \\
\hline SF, Social Functioning & 0.03 & 0.86 & -0.23 & 0.42 & 0.23 & 0.42 \\
\hline RE, Role Emotional & 0.28 & 0.13 & 0.23 & 0.42 & 0.37 & 0.17 \\
\hline MH, Mental Health & 0.12 & 0.52 & -0.26 & 0.35 & 0.48 & 0.073 \\
\hline $\begin{array}{l}\text { Physical Component } \\
\text { Summary (PCS) }\end{array}$ & -0.50 & $0.004 * *$ & -0.55 & $0.032 *$ & -0.41 & 0.13 \\
\hline $\begin{array}{l}\text { Mental Component } \\
\text { Summary (MCS) }\end{array}$ & 0.34 & 0.064 & 0.038 & 0.89 & 0.60 & 0.019* \\
\hline
\end{tabular}


Fig 1

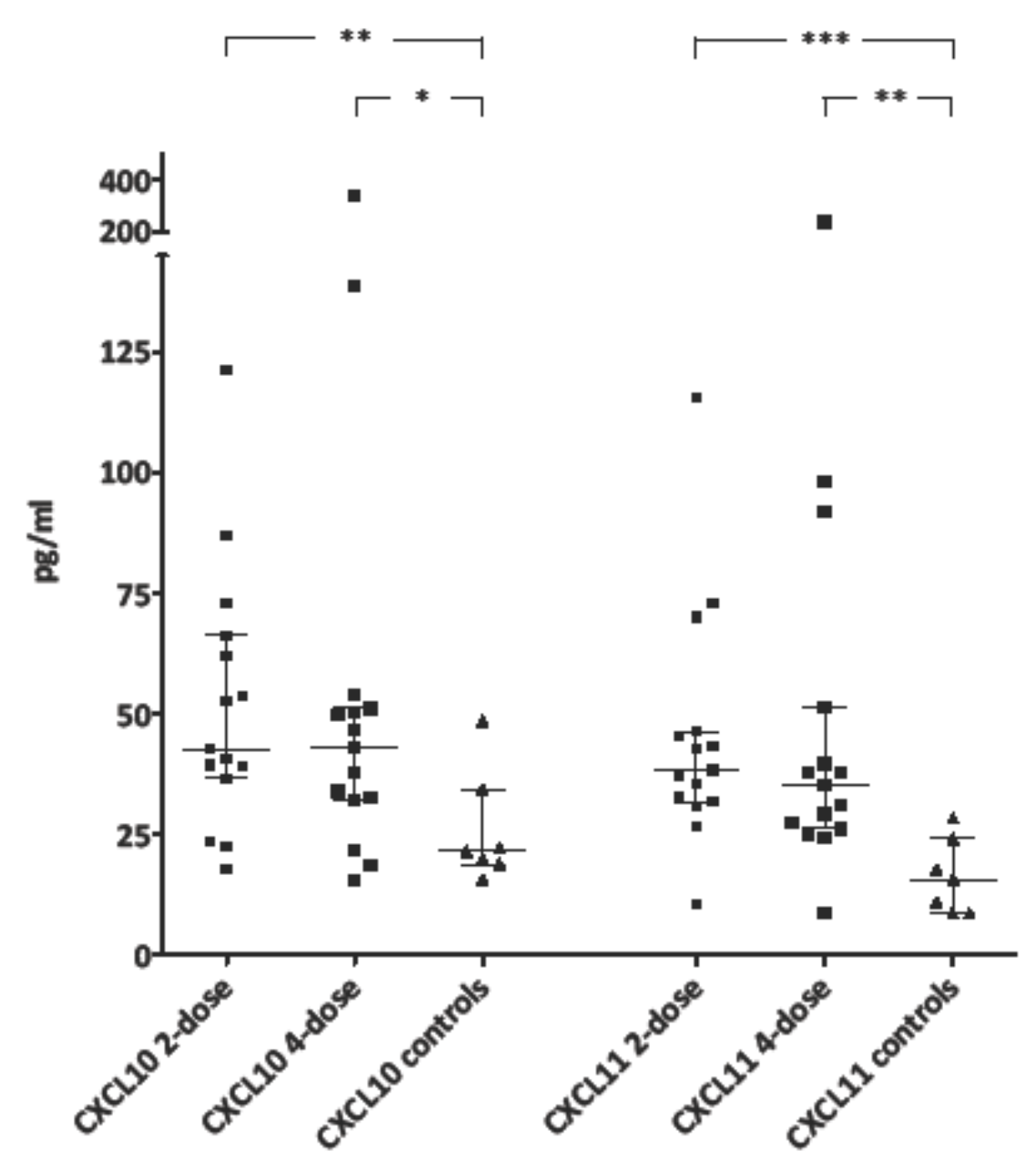

Georg Thieme Publishers KG, Rüdigerstraße 14, 70469 Stuttgart, Germany 

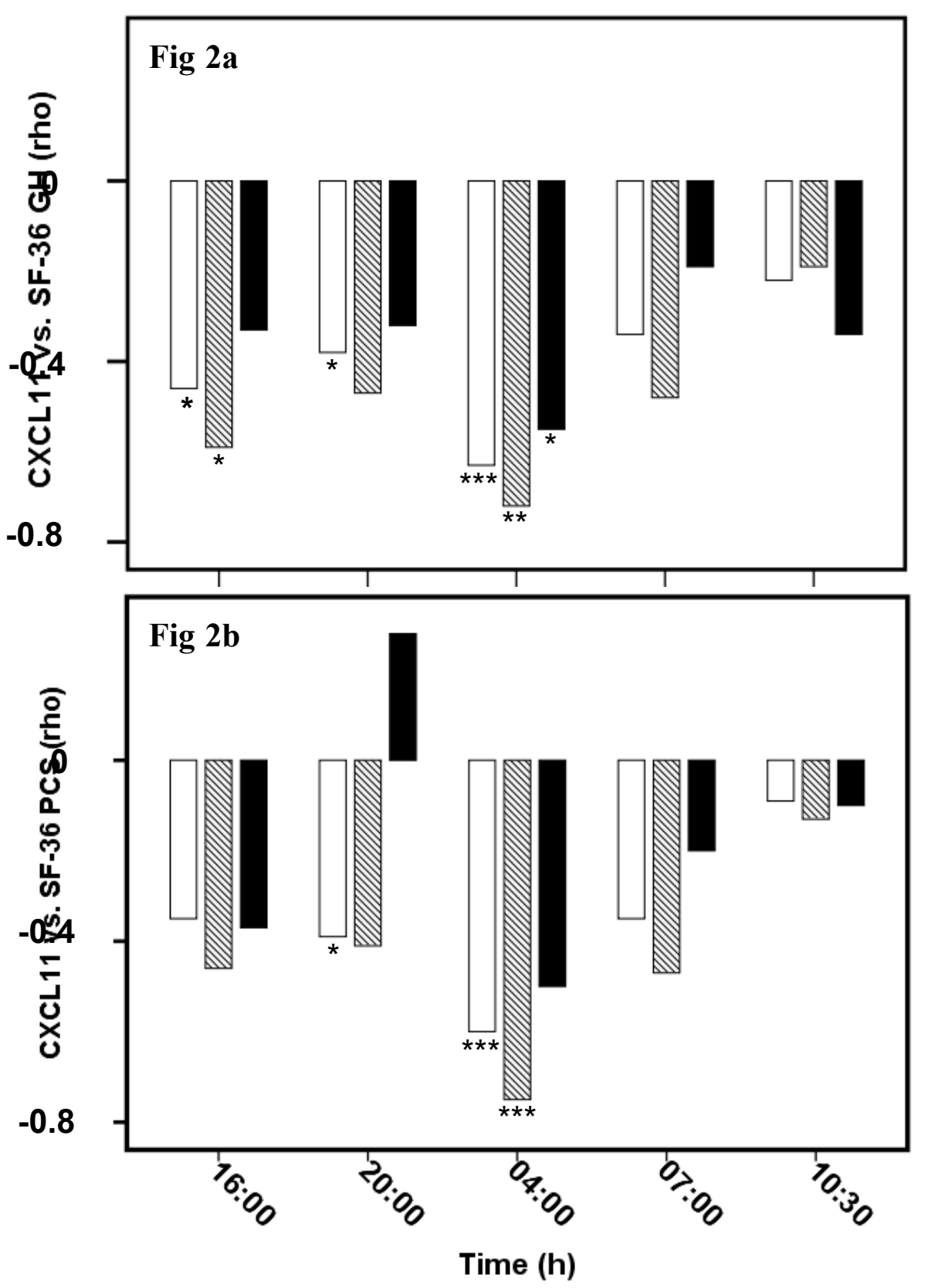

Georg Thieme Publishers KG, Rüdigerstraße 14, 70469 Stuttgart, Germany 